Presented at: 6th International Conference on Synchrotron

Radiation Instrumentation

Himeji, Japan

August 4-8, 1997

$$
\text { CONF-970889-- }
$$

BNL- 65001

Initial Results from an In-Vacuum Undulator in the NSLS X-ray Ring

P. M. Stefan ${ }^{a}$, T. Tanabe ${ }^{b}$, S. Krinsky', G. Rakowsky", L. Solomon", and H. Kitamura ${ }^{b}$

'National Synchrotron Light Source, Brookhaven National Laboratory, Upton, NY 11973-5000, USA

'SPring-8 Project Team, Kamigori, Ako-gun, Hyogo 678-12, Japan

RECEIVED

FFR 101998

O \& TI

November 1997

DWTRBBUTION OF THIS DOCUMENT IS UMUTIED

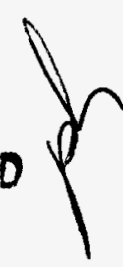

MASTER

National Synchrotron Light Source Brookhaven National Laboratory

Upton, NY 11973

Work performed under the auspices of the U.S. Department of Energy, under contract DE-AC02-76CH00016 


\section{DISCLAIMER}

This report was prepared as an account of work sponsored by an agency of the United States Government. Neither the United States Government nor any agency thereof, nor any of their employees, makes any warranty, express or implied, or assumes any legal liability or responsibility for the accuracy, completeness, or usefuiness of any information, apparatus, product, or process disclosed, or represents that its use would not infringe privately owned rights. Reference berein to any specific commercial product, process, or service by trade name. trademark. manufacturet, or otherwise does not necessarily constitute or imply its endorsement, recommendation, or favoring by the United States Government or any agency thereof. The views and opinions of authors expressed herein do not necessarily state or reflect those of the United States Government or any agency thereof. 


\title{
Initial Results from an In-Vacuum Undulator in the NSLS X-Ray Ring
}

\author{
P.M. Stefan", T. Tanabe ${ }^{b}$, S. Krinsky", G. Rakowsky", L. Solomon"a and H. \\ Kitamurab \\ aNational Synchrotron Light Source, Brookhaven National Laboratory, Upton, New York \\ 11973-5000 USA, and bSPring-8 Project Team, Kamigori, Ako-gun, Hyogo 678-12, JAPAN
}

\begin{abstract}
A short-period, in-vacuum undulator for the NSLS X-Ray Ring has been developed in a collaboration between SPring-8 and the NSLS, and has achieved its project design goals during commissioning studies. The device is called IVUN (In-Vacuum UNdulator) and employs magnet arrays ( 31 periods, with an $11 \mathrm{~mm}$ period) developed at SPring-8, while the requisite vacuum chamber and mechanical systems were developed at the NSLS. At a magnet gap of $3.3 \mathrm{~mm}$, IVUN produces $4.6 \mathrm{keV}$ radiation in the fundamental, with useful photon fluxes in both the 2nd and 3rd harmonics. The magnet gap is adjustable between $2 \mathrm{~mm}$ and $10 \mathrm{~mm}$. A brief overview of IVUN is presented, together with initial commissioning results: the dependence of electron beam lifetime and bremsstrahlung on magnet gap, and the output radiation spectrum.
\end{abstract}

Keywords: undulator; short-period, in-vacuum, small-gap

\section{Introduction}

The development of a short-period, in-vacuum undulator for the NSLS X-Ray Ring is a logical extension of our interest in small-gap, short-period devices. One goal has been to produce hard $\mathrm{x}$-rays from an undulator insertion device in the $2.584 \mathrm{GeV}$ NSLS X-Ray Ring. The basic undulator equations dictate that the device have a short-period. To generate significant photon fluxes from such an undulator, the magnet gap must be smaller than the undulator period, so a small magnet gap is also needed.

Our present device was built in a collaboration between SPring- 8 and the NSLS. The device is called IVUN (In-Vacuum UNdulator) and consists of magnet arrays developed at SPring-8, and vacuum chamber and mechanical systems developed at the NSLS. The design goal is a $3 \mathrm{~mm}$ aperture for the stored beam, with a corresponding magnet gap of $3.3 \mathrm{~mm}, 4.6 \mathrm{keV}$ photon output in the fundamental, and usable flux in both the second and third harmonics.

\section{Description of IVUN}

Two primary requirements shaped the basic conceptual design of IVUN. First, convenient and accurate relative alignment of the magnet arrays, using standard optical survey techniques, must be possible. Second, the arrays must be effectively water-cooled, to remove the heat generated by beam impedance effects (Bane \& Krinsky, 1993) and by the possible interception of synchrotron radiation from the upstream bending magnet. The resulting conceptual design is illustrated in Fig. 1. Magnet arrays are bolted to support beams, which are attached to single tubular columns within a rectangular vacuum tank. Bellows on the vacuum tank permit a drive system (located outside the vacuum) to control the magnet gap. The drive system can

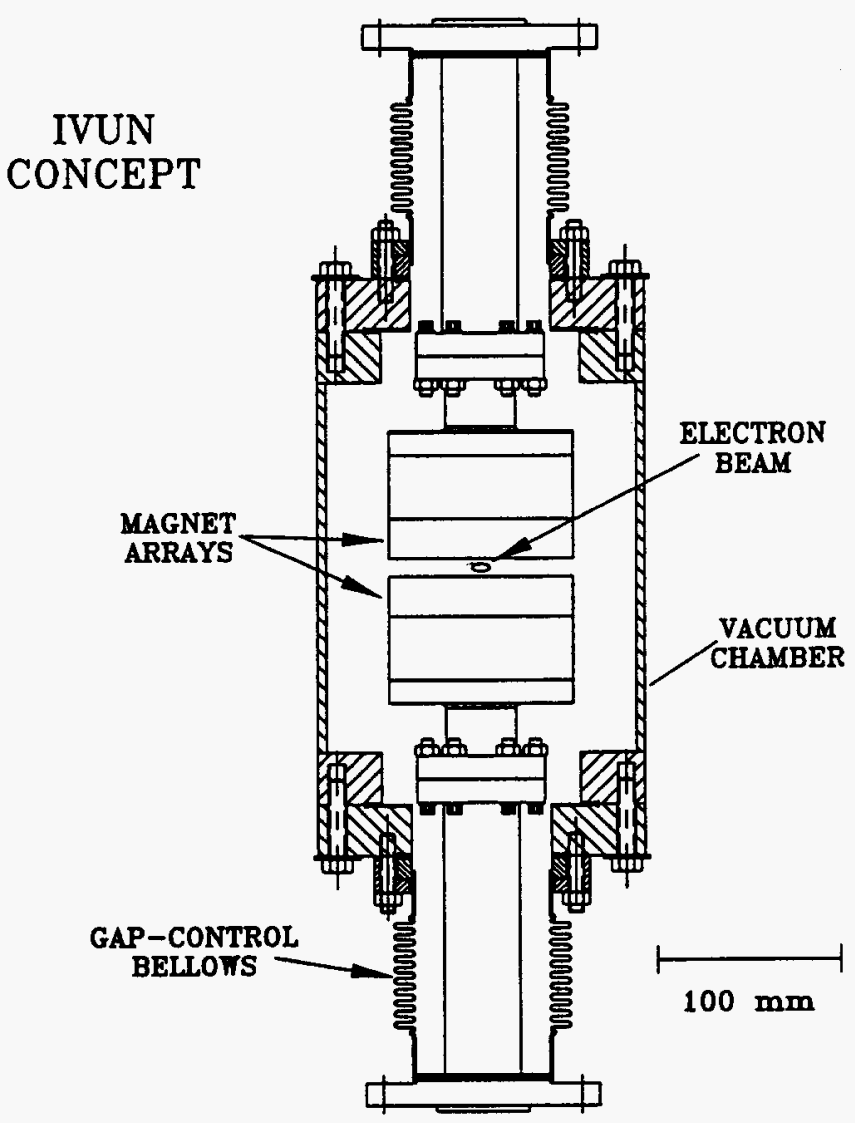

Figure 1

The basic IVUN conceptual design. Magnet arrays are bolted to water-cooled Al bars, which are supported on single tubular columns within a rectangular vacuum tank. Bellows on the vacuum tank permit an external drive system to control the magnet gap. 
open the magnet gap to over $260 \mathrm{~mm}$, permitting installation or removal of the central vacuum chamber. This enables convenient alignment of the magnet arrays. For cooling, the support beams are made of $\mathrm{Al}$ alloys, and are equipped with internally-machined water cooling channels. The cooling lines pass through the open centers of the tubular columns.

The IVUN undulator magnet arrays are constructed with an $11 \mathrm{~mm}$ period, and contain 31 periods. A 4-block pure-permanent-magnet structure is used, with a recentlydeveloped, high-temperature $\mathrm{NdFeB}$ magnet material which permits in-situ bakeout to $125^{\circ} \mathrm{C}$. The blocks are coated with $\mathrm{TiN}$, to enhance ultra-high vacuum compatibility. $\mathrm{Ni}$ strips, $50 \mathrm{~mm}$ wide and $100 \mu \mathrm{m}$ thick cover the magnet arrays and maintain electrical continuity over the arrays. For additional details about the magnet arrays, see the paper by Tanabe, et al. in these proceedings (Tanabe, et al., 1998).

\section{Installation and commissioning results}

IVUN was installed at the center of the X13 R\&D straight section of the NSLS X-Ray Storage Ring in May, 1997, where it replaced the Prototype Small-Gap Undulator (PSGU) device (Stefan \& Krinsky, 1996; Stefan, Krinsky, Rakowsky \& Solomon, 1995; Stefan, Krinsky, Rakowsky \& Solomon, 1996; Stefan, Solomon, Krinsky \& Rakowsky, 1991). For initial conditioning of IVUN, the magnet gap was left at $10 \mathrm{~mm}$. The X-ray Ring presently runs for normal operations at a beam energy of $2.584 \mathrm{GeV}$ and a maximum stored current of $350 \mathrm{~mA}$. The pressure in IVUN, at a stored current of $330 \mathrm{~mA}$, was $7.1 \mathrm{nTorr}$ after about $10 \mathrm{amp}-\mathrm{hr}$ of conditioning, and has decreased to 1.1 nTorr after about $230 \mathrm{amp}$-hr.

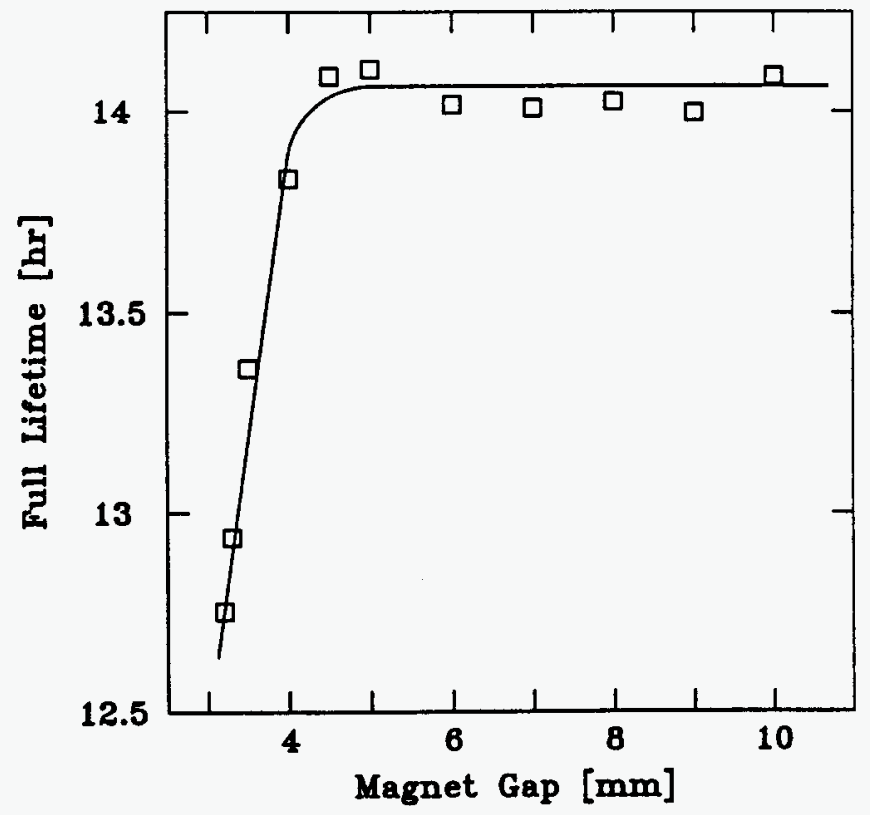

Figure 2

The NSLS X-Ray Ring beam lifetime as a function of the IVUN magnet gap (average stored current of $270 \mathrm{~mA}$ ). The electron beam aperture is $0.3 \mathrm{~mm}$ less than the magnet gap.
During studies periods, IVUN has operated with magnet gaps between $10 \mathrm{~mm}$ and $3.2 \mathrm{~mm}$. As the IVUN magnet gap is decreased from $10 \mathrm{~mm}$, the stored beam lifetime is at first unaffected, but at smaller gaps, the lifetime decreases. This is illustrated in the data presented in Fig. 2. The solid curve is a guide for the eye. Note that the beam lifetime is essentially constant from $10 \mathrm{~mm}$ to 4.5 $\mathrm{mm}$, but then decreases. Even at the $3.2 \mathrm{~mm}$ gap, however, the lifetime has only decreased from $14 \mathrm{hr}$ to about 12.7 hours, which corresponds to a partial lifetime contribution of over $100 \mathrm{hr}$. The lifetime decrease illustrated in Fig. 2 is likely due to glancing collisions of electrons from the outermost tails of the stored beam vertical distribution with the IVUN magnet arrays. This conjecture is supported by simultaneous measurements of the bremsstrahlung dose rate, using a detector located in the X13 beamline experimental hutch. These data are presented in Fig. 3. The solid curve in the figure is again a guide for the eye.

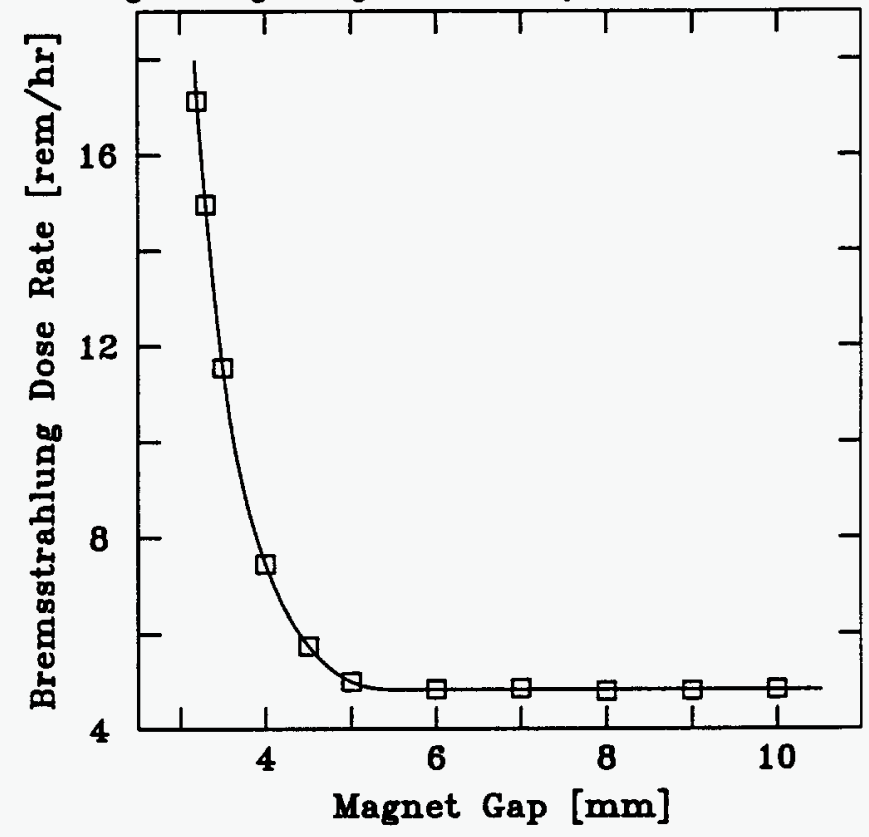

\section{Figure 3}

The bremsstrahlung dose rate from the X13 straight section as a function of the IVUN magnet gap. The constant rate seen for magnet gaps between $10 \mathrm{~mm}$ and $5 \mathrm{~mm}$ is due to electron collisions with residual gas molecules in the straight section.

The dose rate reported assumes a bremsstrahlung beam dimension of $15 \mathrm{~mm}$ vertical and $20 \mathrm{~mm}$ horizontal at the detector location, $27 \mathrm{~m}$ from the IVUN source. The constant dose rate of about $5 \mathrm{rem} / \mathrm{hr}$ (for magnet gaps between $10 \mathrm{~mm}$ and $5 \mathrm{~mm}$ ) is due to interaction of the stored electron beam with residual gas molecules in the $11.31 \mathrm{~m}$ long straight section. The noise level in these measurements is less than that in the lifetime measurements, and suggests that electrons begin to be intercepted on the IVUN arrays for magnet gaps less than $5 \mathrm{~mm}$. This result is consistent with similar measurements conducted with the 
PSGU (Stefan \& Krinsky, 1996).

The photon spectrum emitted by IVUN was measured in the X13 beamline hutch using a single-crystal spectrometer (the same system used for PSGU measurements) (Stefan, Krinsky, Rakowsky \& Solomon, 1995). The entrance slit was located about $25.3 \mathrm{~m}$ from IVUN, and was $1 \mathrm{~mm}$ high and $40 \mathrm{~mm}$ wide. A controlled atmosphere of either $\mathrm{N}_{2}$ or $\mathrm{He}$ surrounded the entire spectrometer. This atmosphere served as a filter/transport gas and as the detector gas for the open ion chamber. Helium gas is useful for photon energies below about $6 \mathrm{keV}$, while $\mathrm{N}_{2}$ is useful above about $4 \mathrm{keV}$. A spectrum collected at an IVUN gap of $3.31 \mathrm{~mm}$ is presented in Fig. 4.

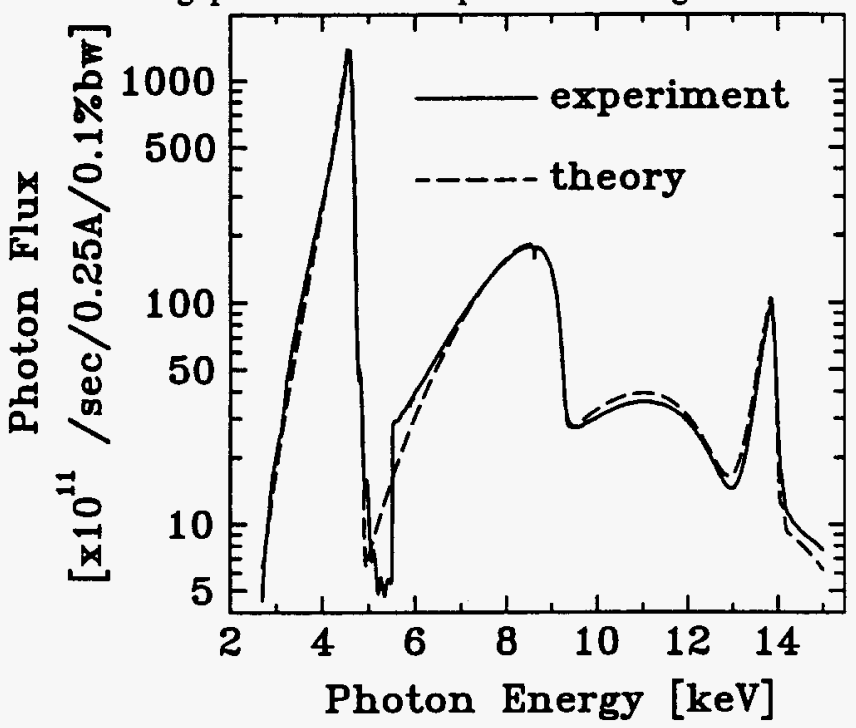

Figure 4

The photon spectrum emitted by IVUN at a magnet gap of $3.31 \mathrm{~mm}$. The theory curve was obtained using the URGENT code (Walker \& Diviacco, 1992).

The three highest peaks are the fundamental (at about 4.6 $\mathrm{keV}$ ), the second harmonic (which has a maximum at 8.67 $\mathrm{keV}$ ) and the third harmonic (at about $13.8 \mathrm{keV}$ ), respectively. The discontinuity seen at $5.5 \mathrm{keV}$ is the splice point between the spectrum taken with He (lower energies) and that taken with $\mathrm{N}_{2}$ (higher energies). The raw data is processed without adjustable parameters. Corrections are applied for x-ray attenuation by the $254 \mu \mathrm{m}$ thick Be window and the transport column of gas, and for the energydependent detection efficiency of the ion chamber. The bandwidth of the $\mathrm{Si}(111)$ crystal is accounted for as a simple multiplicative factor. The theory curve is obtained using the URGENT code (Walker \& Diviacco, 1992), for which the input parameters are 1) the basic undulator dimensions, 2) the deflection parameter, $K, 3$ ) the storage ring beam energy, current, and emittances, and 4) the location and size of the spectrometer entrance slit. The agreement between experiment and theory is good. Even the intensity of the third harmonic is only slightly below the theory value. The brightness at the peak of the fundamental at $4.6 \mathrm{keV}$ is $3 \mathrm{x}$ $10^{17}$ photons $/ \mathrm{sec} / 0.25 \mathrm{amp} / \mathrm{mm}^{2} / \mathrm{mrad}^{2} / 0.1 \%$ bandwidth.

\section{Conclusion}

The NSLS / SPring-8 in-vacuum short-period undulator, IVUN, has been successfully operated in the NSLS X-Ray Storage Ring, in the X13 R\&D straight section. IVUN operation is compatible with normal ring operations at the design magnet gap of $3.3 \mathrm{~mm}$. Lifetime degradation is small and tolerable. The performance of IVUN, as measured by the photon output spectrum, agrees with theory.

\section{References}

Bane, K. \& Krinsky, S., (1993). Proceedings of the 1993 Particle Accelerator Conference, Washington, DC, 3375-3377.

Stefan, P.M. \& Krinsky, S., (1996). Rev. Sci. Instrum., 67(9), 3346. (Full text on CD ROM only.)

Stefan, P.M., Krinsky, S., Rakowsky, G. \& Solomon, L., (1995). in The Art and Science of Magnet Design, LBL PUB-754, 161-173.

Stefan, P.M., Krinsky, S., Rakowsky, G. \& Solomon, L., (1996). Proceedings of the 1995 Particle Accelerator Conference, Dallas, TX, 2435-2437.

Stefan, P.M., Solomon, L., Krinsky, S. \& Rakowsky, G. (1991). Proceedings of the 1991 Particle Accelerator Conference, San Francisco, CA, 10961098.

Tanabe, T., et al., (1998). These proceedings.

Walker, R.P. \& Diviacco, B., (1992). Rev. Sci. Instrum., 63(1), 392-395. 


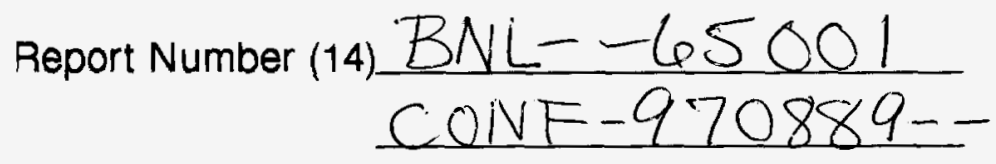

Jubl. Date (11)

Sponsor Code (18)

JC Category (19)

$\frac{\frac{19011}{\text { DOE/ER, XF }}}{\text { UC-4OY,DOE/ER }}$

